\title{
How to Improve the Quality of Youth Education in Developing Countries
}

\author{
Yijun Chen
}

\author{
YK Pao School \\ *Corresponding author. Email: Yijun2169@163.com
}

\begin{abstract}
The United Nations Sustainable Development Goals set out clear requirements for improving the quality of education and protecting the well-being of children. As a unique social group that is vulnerable to adverse environmental factors, adolescents having timely access to quality education is of great importance to themselves and society. While there has been a significant increase in primary education enrolment in developing countries, lots of children are still out of school. Moreover, 617 million adolescents worldwide lack basic mathematics and literacy skills. This paper looks at the plight of youth education in developing countries, analyzing the impact of the economic situation, attacks and conflicts, as well as pandemics and disasters on the quality of education. It proposes countermeasures and recommendations on how to improve education quality at the levels of national policy and support, quality and quantity of teachers, avoidance of discrimination and bullying in schools, Internet information technology, international economic and technical assistance, and multilateral cooperation and exchange. Governments should actively implement measures based on practice and promote the quality of youth education as a priority.
\end{abstract}

Keywords: Youth education, Quality of education, Developing country, Measure.

\section{INTRODUCTION}

Everyone has the right to receive an education. The fourth goal of the 17 Sustainable Development Goals of the United Nations (SDG 4) is about the quality education. It aims to ensure inclusive, equitable quality education and promote lifelong learning opportunities for all by 2030. However, this goal is facing great challenges. A total of 258 million children and young people, around one-sixth of the global school-age population, remained out of school, and the vast majority of them live in developing countries[1]. For example, in sub-Saharan Africa, 41 percent of school-age children did not finish primary school, and 87 percent did not reach the minimum proficiency level in reading. The international community commits to achieving universal high school education by 2030, but the completion rate of Burkina Faso and Niger is only 2 percent[2].

In contrast to the harsh reality is children's aspirations. In a survey[3] of more than 2,000 children from developing countries including Ethiopia, India, Peru and Vietnam, children showed high expectations for education, which was regarded as the primary way to get rid of poverty, help families, engage in better occupation and achieve socioeconomic mobility. At the same time, from a social perspective, if adolescents have sustained access to quality education, it helps reduce inequalities, improve people's literacy, promote economic and scientific development, and make a significant contribution to achieving a sustainable life. As a result, it is of great significance and practical value to study how to improve the quality of youth education in developing countries.

\section{THE PLIGHT OF YOUTH EDUCATION IN DEVELOPING COUNTRIES}

\subsection{A dire economic situation}

According to the global education monitoring report, the total annual expenditure on education for all countries is $\$ 4.7$ trillion, of which 65 percent is spent in high-income countries and only $\$ 22$ billion ( 0.5 percent of the total) is spent in low-income countries, although the number of school-age adolescents in the two groups of countries is roughly the same. The lack of economic investment has led to the inability of many developing countries to build sufficient educational infrastructure in 
specific regions, hire excellent and committed teachers, and obtain high-quality educational resources. Muhammad Rezza, a 10th-grade student in Afghanistan, said that sometimes teachers did not show up to class because the school was quite far away, and there was no road for the teachers to drive on. They had no electricity and no toilet. It was freezing in winter and there was no heating. Their teachers tried to teach all of them, but there were not enough books and desks. In $2015,40 \%$ of principals in Indonesia and Jordan said that infrastructure problems affected teaching seriously[4].

\subsection{Growing attacks and conflicts}

In developing countries with weak education systems, attacks and conflicts have had a severe impact on universal access to quality education. The World Bank estimates that approximately 50 percent of out-of-school children live in conflict-affected areas. The Syrian civil war resulted in nearly 2 million Syrian children dropping out of school in 2013. As at March 2021, 687,611 Syrian refugee children aged 3 to 18 in Lebanon needed access to education services. To make matters worse, schools, teachers and students became the targets of attacks[5]. Data shows that attacks against schools have been on a rapid rise since 2004, and are particularly evident in South Asia, North Africa and other regions. Schools have been occupied, bombed and destroyed, students have been killed or kidnapped. Between 2015 and 2019, more than 11,000 attacks or military use of educational facilities were reported worldwide. These incidents have hurt more than 22,000 students as well as education staff, and exacerbated dropouts, teacher shortages and school closures[6].

\subsection{Frequent disasters}

Cyclones, typhoons, floods, droughts, epidemics and other disasters are never far from human beings. The COVID-19 pandemic has been ongoing, and education for millions of children worldwide is still disrupted. As of July 2021, primary and secondary schools in 19 countries were shuttered, affecting over 156 million students[7]. Covid-19 has left a lasting imprint on the world. In addition, the world has seen thousands of climate-related shocks and food crises in the past three decades. Families in many developing countries are unable even to feed their children, let alone pay for education. During the drought-prone area, the student dropout rate was as high as 50 percent in the Democratic Republic of the Congo. Children in these countries were 30 percent less likely to complete primary school and 50 percent less likely to complete lower secondary school compared with children in countries not affected by crisis[8].

\section{THE SOLUTION TO THE PROBLEM}

\subsection{National policies and support}

Firm and coherent policies are the basis for improving the quality of education. Developing countries, in particular, need to develop solid and diversified education policies and strategies, and supervise the implementation of these policies actively. Governments have essential responsibilities and play a pivotal role in this regard. Specific policies should reach into all aspects of the education system. For instance, first, governments should actively implement free and compulsory education, require adolescents to attend an appropriate level of compulsory education, ensure the duration of education, prevent school dropout and make it easier for students to get access to a better education. The global education monitoring report shows that in 2020 , less than $20 \%$ of countries worldwide guarantee at least twelve years of free and compulsory education within a legal framework. While 70 percent of countries provide at least nine years of compulsory education, only 40 percent of countries in sub-Saharan Africa are able to do so[9].

Second, governments should focus on policies that favor vulnerable groups as well as disadvantaged areas. Targeted scientific measures are important to protect the legal right to education of girls, children with disabilities and children in low-income areas. In Nigeria, the enrollment rate of girls was once half or less than that of boys. The government has issued a national basic education program, opted for balanced development in the allocation of educational resources, provided policy support to poor areas and educationally backward areas, and made well-meaning attempts to weaken the marginalization of the poor as well as discrimination against minority tribes and narrow the education gap between local areas. However, some governments have not systematically incorporated education for sustainable development into their specific policies, although they have put forward the requirements of carrying out education for sustainable development. It results in unbalanced development of education in various regions, groups, and schools, which has restricted education quality improvement.

Third, governments need to increase the investment in education. In 2020, a quarter of the countries for which data are available spent less than 4 percent of GDP on education and allocated less than $15 \%$ of public spending to education[10], falling short of the minimum requirements set out in the 2030 Education Framework for Action. Developing countries should actively strengthen education infrastructure, such as building qualified schools, promoting educational welfare projects including the provision of free textbooks, school meals, and transportation to and from school, setting up grants for poor students, providing quality 
training for teachers, and eliminating additional fees for education.

\subsection{Quality and quantity of teachers}

Quality education is the result of the interaction of many factors, one of the most important of which is quality teachers and teaching. There is a shortage of well-trained teachers worldwide. According to UNESCO estimates, 69 million teachers must be recruited by 2030 to achieve universal primary and secondary education[11]. Many countries face the twin challenges of shortage of teachers and poor teacher quality. Therefore, it is imperative to significantly increase the number of qualified teachers by improving their training, recruitment, retention, status, working conditions and motivation. For example, countries should provide quality training to improve teachers' abilities, supplement the teaching force by rehiring retired teachers and promoting mobile teaching, set benefits and incentives for teachers to optimize their commitment and attract talents. In addition to improving teachers' economic benefits, developing countries should also protect teachers' social status and promote a good atmosphere of respect for teachers and education in society.

\subsection{Avoidance of school bullying and discrimination}

Discrimination and bullying in the educational environment violate the fundamental human rights of adolescents, exposing them to fear, depression, anger, low self-esteem, and other stresses that seriously affect their regular learning. In an international student assessment project, the proportion of 15-year-old students who reported that they had suffered such bullying reached more than 25 percent in the Dominican Republic, Latvia and Tunisia. Students experience discrimination and bullying because of gender, ethnicity, language, poverty, disability, and other factors[12]. In this regard, governments at all levels, the judiciary, schools and teachers should express zero tolerance, implement legal rules and standards of behavior fairly and consistently, intervene promptly, and pay attention to monitoring and evaluation. Students need a learning environment where they feel safe and supported, which helps them focus on studying and achieve better learning outcomes. Achieving such a goal requires concerted efforts by all parties.

\subsection{Internet Information technology}

The advent of the Internet has opened up opportunities for the education of disadvantaged children. The power and convenience of the internet allow them to overcome problems of time, space and distance, to receive quality teaching resources from around the world in a flexible way, and to provide them with equal educational opportunities with children from other regions or non-disadvantaged children, as well as the opportunity to connect with the wide world. Its significance is not only in daily life but also during conflicts, disasters and epidemics, which means adolescents can still get access to education through the network in these tough times. In order to achieve a rational use of internet technology, developing countries should pay attention to the construction and management of network infrastructure, actively explore the integration of online learning resources with school teaching models, and develop campus network safety policies to protect students' safe and healthy access to the internet. When there are technical and equipment barriers, combining mobile phones, DVD videos and other alternative ways to learn should be considered. For example, UNESCO's Mobile Literacy Project in rural Pakistan, which uses mobile devices like smartphones to deliver literacy courses to female adolescents, has increased the proportion of students achieving excellent grades from 28 percent to 60 percent[13].

\subsection{International economic and technical assistance}

To achieve the 2030 goal of education for sustainable development, including quality education, developing countries need to actively explore and practice at home and cooperate with other countries and international agencies. In 2015, based on the World Declaration on Education for All and the Dakar Framework for Action, UNESCO clearly stated that the shortage of education funds in developing countries should be made up by international funds such as official development assistance. However, there is a long-term funding gap in education aid currently, and the level of aid is far below what is needed to achieve the goals. As official development assistance is the "most critical resource for education finance" in developing countries[14], the governments of developed countries, economically rich countries and newly industrialized countries and their subordinate institutions should actively fulfill their commitments by providing financial assistance, including grants, human and technical support, and long-term, interest-free or low-interest loans on favorable terms. Developing countries should focus on the principle of joint infrastructure and capacity building when receiving aid, so that more students, teachers and schools can benefit directly and the quality of education will be improved.

\subsection{Multilateral cooperation and exchange}

In the context of strengthening the trend of globalization, international exchanges and cooperation on education quality continue to develop in depth. Developing countries should learn from the education 
policies, development concepts and reform measures of developed countries in a planned and selective manner, taking into account their own realities and characteristics, and try to find the most suitable education programs and development strategies for their cultural environment. The World Bank also pointed out that the risk is higher when the experience extracted from the better-based education systems of developed countries is inappropriately transplanted to developing countries. [15] On the other hand, when the education pilot programs led by international organizations, such as United Nations International Children's Emergency Fund's "Connect My School" internet project in Cameroon[16], have yielded positive results, or when some developing countries have formed successful and innovative programs in practice, such as Ethiopia's joint school-based teacher professional support system[17], it is essential to share and disseminate these experiences to help developing countries gain better solutions to the challenges they face.

In addition, according to UNESCO's 2030 Education Framework for Action, the monitoring framework for quality education as a sustainable development goal has dozens of indicators for consideration. While promoting education construction, developing countries should establish a scientific education quality assessment and feedback system to evaluate the curriculum system, teacher training, school construction, teaching results, and the effectiveness of aid, then make reasonable adjustments to policies and measures according to the actual local situation, strive to improve the quality of education and protect the rights of adolescents effectively.

\section{CONCLUSION}

To sum up, developing countries are facing a major test in securing and improving the quality of youth education as the COVID-19 pandemic spread across the globe. Governments should prioritize improving the quality of education in their policies and practices, strengthen national policy support, improve the quality and quantity of teachers, avoid discrimination and bullying in schools, make appropriate use of the internet information technology, and strengthen international assistance and multilateral cooperation. The global community needs to actively promote the implementation of SDG 4, and ensure inclusive, equitable and quality education for adolescents.

\section{REFERENCES}

[1] Emma Wagner. Build-Forward-Better 2021 UK savethechildren.net.

[2] United Nations Educational, Scientific and Cultural Organization. 2017 Global Education Monitoring Report. 2017/8.
[3] Nichole Torpey Saboe. Measuring Education Inequality in Developing Countries. Springer, Cham, 2019.

[4] United Nations Educational, Scientific and Cultural Organization. 2017 Global Education Monitoring Report. 2017/8.

[5] United Nations Educational, Scientific and Cultural Organization. Back to school: Syrian children in Bekaa refugees camps resume learning at UNESCO schools 2021.9. Retrieved Aug. 20, 2021, from https://en.unesco.org/news/back-school-syrian-chil dren-bekaa-refugees-camps-resume-learning-unesc o-schools

[6] United Nations Educational, Scientific and Cultural Organization. Back to school: Syrian children in Bekaa refugees camps resume learning at UNESCO schools 2021.9. Retrieved Aug. 20, 2021, from https://en.unesco.org/news/back-school-syrian-chil dren-bekaa-refugees-camps-resume-learning-unesc o-schools

[7] United Nations Educational, Scientific and Cultural Organization. Reopening schools cannot wait: joint statement by UNICEF and UNESCO 2021.7.12 Retrieved Aug. 20, 2021, from https://en.unesco.org/news/reopening-schools-cann ot-wait-joint-statement-unicef-and-unesco

[8] Emma Wagner. Build-Forward-Better .2021 .UK savethechildren.net.

[9] United Nations Educational, Scientific and Cultural Organization. 2017 Global Education Monitoring Report. 2017/8.

[10] United Nations Educational, Scientific and Cultural Organization. 2017 Global Education Monitoring Report. 2017/8.

[11] United Nations Educational, Scientific and Cultural Organization. Teachers. 2021. Retrieved Sep.5, 2021, from https://en.unesco.org/themes/teachers

[12] United Nations Educational, Scientific and Cultural Organization. Violence and Bullying in Educational Settings. 2021. Retrieved Sep.5, 2021, from

https://unesdoc.unesco.org/ark:/48223/pf00003780 61

[13] United Nations Educational, Scientific and Cultural Organization. Mobile Phones \&Literacy: Empowerment in Women's Hands[R]. Paris: UNESCO, 2015:46. 
[14] Renqin Xia. MinxuanZhang. Official development assistance: an indispensable source of funding for global education development. Comparative Education Research 39.04(2017):15-22. doi:CNKI:SUN:BJJY.0.2017-04-002.

[15] Heneveld, Ward.\& Craig, Helen. Schools Count: World Bank Project Designs and the Quality of Primary Education in Sub-Saharan Africa[M]. Washington, D.C. : The World Bank.1996.8.11.13. 15.16. 17.18.

[16] Rong Fang and Linshuai Kong. UNICEF's approach to promoting education for disadvantaged children in the digital age - the example of the Connect My School project. Foreign primary and secondary education. 09(2019):27-31. doi:CNKI:SUN:WGZX.0.2019-09-004.

[17] Jing Liu. Professional Development Support Systems for Rural Teachers - Practices in Developing Countries. Comparative Education Studies. $36.01(2014): 25-30$. doi:CNKI:SUN:BJJY.0.2014-01-005. 